\title{
THE ROLE OF GUSTATORY AND POSTINGESTIVE SIGNALS IN THE TERMINATION OF DELAYED GLUCOPRIVIC FEEDING AND HYPOTHALAMIC NOREPINEPHRINE TURNOVER ${ }^{1}$
}

\author{
SUE RITTER, ${ }^{2}$ STEVEN I. BELLIN, ${ }^{3}$ AND NANCY L. PELZER \\ Department of Veterinary and Comparative Anatomy, Pharmacology and Physiology, College of Veterinary Medicine, Washinglun State \\ University, Pullman, Washington 99164
}

\begin{abstract}
If food is withheld for $6 \mathrm{hr}$ after insulin injection, enhanced feeding in response to glucoprivation can still be demonstrated even though blood glucose has returned spontaneously to normal. Moreover, the magnitude of the glucoprivic feeding is unattenuated by the delay. Like feeding, glucoprivation-induced increases in hypothalamic norepinephrine (NE) turnover also persist after the spontaneous return to normoglycemia, fostering the notion that these neurons may mediate the feeding. Rats were allowed restricted access to saccharin $(0.1 \%$ solution) or isocaloric quantities of D-glucose or D-fructose (18\% solutions), fat (lard), or pelleted rat food during a 30-min period 1.5 to $2 \mathrm{hr}$ after insulin ( 2.5 units $/ \mathrm{kg}$, s.c.) or saline injection in order to specify the conditions responsible for the termination of the glucoprivic stimulus to feed and to determine whether these same conditions would be associated with normalization of NE turnover. Delayed feeding was measured in a 2-hr test 4 to $6 \mathrm{hr}$ later. Nutrients were selected for their differences as substrates for brain energy metabolism and their caloric values were equated with the number of calories $(7.9 \mathrm{kcal})$ which abolishes delayed glucoprivic feeding (DGF) when ingested as pelleted food. Norepinephrine turnover (the decline of NE concentrations after synthesis inhibition with $\alpha$-methyl- $p$-tyrosine) was normalized after glucoprivation by ingestion of pelleted food and glucose but was unaltered by ingestion of fructose or fat or by non-nutritive orogastric stimulation. Similarly, DGF was totally abolished only by ingestion of glucose or pelleted food and was unaffected by non-nutritive substances. However, fructose and lard significantly attenuated the fecding response. Thus, the activity of $\mathrm{NE}$ neurons may be controlled by substrate availability to the brain, whereas the termination of glucoprivic feeding may require the cooperative action of both central and peripheral signals.
\end{abstract}

Systemic or cerebral glucoprivation elicits food intake in the rat and most other mammals (Mackay et al., 1940; Miselis and Epstein, 1975; Engeset and Ritter, 1980; Slusser and Ritter, 1980; Smith and Epstein, 1969; Houpt and Hance, 1977; Houpt, 1974; Thompson and Campbell, 1977). In addition, glucoprivation increases hypothalamic norepinephrine (NE) turnover (Ritter and Neville, 1976; McQueen et al., 1976; McCaleb et al., 1979; Bellin and Ritter, 1981a). Since NE itself elicits feeding when infused into the hypothalamus (Grossman, 1960, Slangen and Miller, 1969; Liebowitz, 1975; Ritter and Epstein, 1975; Ritter et al., 1975), it has been suggested that NE neurons are involved in the control of glucoprivic feeding.

\footnotetext{
' This work was supported by Public Health Service Grants NS14450 and $\mathrm{AM} 28087$ to $\mathrm{S}$. $\mathrm{R}$.

${ }^{2}$ To whom correspondence should be addressed.

3 This paper was submitted in partial fulfillment of the requirements for a doctoral degree. S. I. B. is currently a postdoctoral fellow at the University of Iowa, Department of Psychology.
}

Recently, we have reported that, if food is withheld during insulin-induced glucoprivation, both increased feeding and hypothalamic NE turnover persist even after blood glucose concentrations have returned spontaneously to normal. However, if the animals are allowed to eat as little as $30 \%(2.5 \mathrm{gm})$ of the amount of food that they would have eaten had the food been continuously available during the glucoprivic episode, both the delayed feeding and the concurrent increased hypothalamic NE turnover rate are abolished (Bellin and Ritter, 1981a).

The relatively small amount of food that must be consumed during glucoprivation in order to abolish delayed feeding and normalize NE turnover rates suggests that termination of these responses may not depend entirely upon postabsorptive caloric effects of the ingested food. However, the complexity of the diet used in these experiments (pelleted rodent chow) precluded the identification of the specific parameters of food intake that might be involved in the termination of these two responses. 
In the following experiments, we varied the quantity of pelleted food that animals were allowed to eat during the 30-min glucoprivic feeding period and, in addition, we utilized a number of simpler dietary substances in order to identify the specific aspects of ingestion responsible for the normalization of NE neuron activity and for the abolition of feeding following a glucoprivic episode. After determining an approximate threshold amount of pelleted food necessary to normalize these postglucoprivic events, the effectiveness of glucose, fructose, and lard, ingested in quantities which were equicaloric with the threshold amount of pelleted food, were evaluated.

Because both central and peripheral controls of glucoprivic feeding have been proposed (Smith and Epstein, 1969; Friedman et al., 1973; Epstein et al., 1975; Grossman, 1975; Miselis and Epstein, 1975; Russek, 1975; Friedman and Stricker, 1976; Stricker et al., 1977; Stricker and Rowland, 1978; Rowland and Stricker, 1979), we selected the dietary substances to be used in our experiment on the basis of their differing abilities to serve as substrates for brain metabolism. Ingestion of both pelleted food and glucose rapidly elevate blood glucose concentrations and therefore provide a substrate for brain metabolism. Conversely, under our experimental conditions, neither fructose nor lard are likely to provide metabolic energy for the brain (Goodman, 1970; Oldendorf, 1971; Spitzer, 1973). All four foods, however, provide nourishment for most peripheral tissues. Saccharin, a non-nutritive substance which is relatively palatable and readily consumed (Smith et al., 1980; Smith and Foster, 1980), also was tested in order to assess the role of the preabsorptive sensory aspects of food intake in the absence of postabsorptive caloric effects. Finally, we tested rats with fructose-flavored cardboard to assess the role of orosensory stimulation alone.

Our results reveal that the glucoprivation-induced increase in hypothalamic NE turnover can be reversed by ingestion of nutrients which provide substrates for brain energy metabolism. However, the conditions required for the abolition of delayed feeding are more complex and may involve a constellation of pre- and postabsorptive stimuli.

\section{Materials and Methods}

Adult male Sprague-Dawley rats weighing 400 to 500 gm were used in all studies. They were housed individually in suspended wire mesh cages located in a temperature-controlled room $\left(22 \pm 1^{\circ} \mathrm{C}\right)$ which was illuminated for $12 \mathrm{hr}$ during the day (7 A.M. to 7 P.M.). Experiments were conducted in the animal's home cage during the light period. Pelleted rat food and tap water were freely available to all rats except when noted.

The basic experimental protocol used in all studies was as follows: (1) rats were given free access to fresh pelleted food from 8 to 9 A.M.; (2) food was removed and insulin (Iletin, Lilly, 2.5 units $/ \mathrm{kg}$, s.c.) or saline was injected at 9 A.M.; (3) food was withheld for $6 \mathrm{hr}$ except during a 30 -min period from 1.5 to $2 \mathrm{hr}$ post-insulin injection, during which time, insulin-treated rats were allowed to eat a predetermined quantity of a selected food (identified below); (4) food intake or catecholamine turnover was measured during the postglucoprivic period 6 lo $8 \mathrm{hr}$ after insulin or saline injection. When blood glucose determinations were required, $30 \mu \mathrm{l}$ of blood was collected from the tail vein in microcapillary tubes at $0,1.5,3,4,5$, and $6 \mathrm{hr}$ after insulin or saline injections and assayed using the glucose oxidase method (Saifer and Gerstenfeld, 1958). When catecholamine turnover was measured, rats were injected subcutaneously with $350 \mathrm{mg} / \mathrm{kg}$ of $\alpha$ methyl-p-tyrosine (AMT, $100 \mathrm{mg} / \mathrm{ml}$ of distilled water) $5.5 \mathrm{hr}$ after insulin injection and sacrificed $0.5,1$, and 2 $\mathrm{hr}$ later in the absence of food (Costa, 1970; Weiner, 1974; Cooper et al., 1978; Bellin and Ritter, 1981a). The hypothalamus and telencephalon were dissected, as described by Lorden et al. (1975), and analyzed fluorometrically for catecholamine content using a modification of the method described by Jacobowitz et al. (1967).

In a preliminary experiment, insulin-treated rats were presented with varying quantities of pelleted rat food $(0$, $0.2,1.0$, and $2.5 \mathrm{gm}$ ) during the 30 -min restricted feeding period in order to determine the approximate lower limit of food consumption required to abolish delayed glucoprivic feeding. The effect of these same quantitics of food on blood glucose concentrations was determined in a similar experiment conducted 2 days later. The results revealed that the quantities of pelleted food less than 2.5 gm had no effect on the magnitude of delayed glucoprivic feeding. Therefore, in experiments (described below) designed to isolate various parameters of food intake capable of modulating delayed glucoprivic feeding and/or catecholamine turnover, $2.5 \mathrm{gm}$ of pelleted food, nutrients which were calorically equivalent to $2.5 \mathrm{gm}$ of pelleted food $(7.9 \mathrm{kcal})$, and noncaloric substances were tested.

During the course of base line control studies (conducted at least 2 days prior to experimental feeding trials), both delayed feeding in response to subcutaneous saline injection $(1.0 \mathrm{ml} / \mathrm{kg})$ and blood glucose determinations were assessed in independent studies. Rats that consumed more than $2.5 \mathrm{gm}$ during the base line feeding trial were eliminated from further testing. Using a modified Latin square design (5 animals/group), the following substances were presented to insulin-treated rats during the $30-\mathrm{min}$ restricted feeding period: no food, $2.5 \mathrm{gm}$ of pelleted food, $0.9 \mathrm{gm}$ of lard, $10.5 \mathrm{ml}$ of an $18 \%$ D-glucose solution, or a $0.1 \%$ sodium saccharin solution $(\bar{X}=6.6 \pm$ $1.7 \mathrm{ml}$ ). Consumption of pelleted food was measured to the nearest $0.1 \mathrm{gm}$ in a $2-\mathrm{hr}$ postglucoprivic feeding test beginning $4 \mathrm{hr}$ later. Our modification of the basic Latin square design was that, every other day, a base line feeding trial was conducted. By alternating experimental and base line trials, we insured that no animal received insulin on 2 successive days. This procedure also allowed us to identify and eliminate from statistical evaluation subjects that might have become conditioned to the return of fresh pellets at 3 P.M. each day. Since base lines remained low through the testing, no subjects were eliminated. Rats were pretrained with the novel foods to assure that most animals would consume the required amounts during the experiment.

Three additional treatment groups were included in the delayed feeding experiment. In the first, 6 rats were given $10.5 \mathrm{ml}$ of an $18 \% \mathrm{D}$-fructose solution during the 30 -min restricted feeding period. In the second, 10 rats were given access to two squares (approximately $3.0 \mathrm{~cm}^{2}$ ) of corrugated cardboard that had been dipped briefly in a fructose solution and air dried and then were observed 
every 30 sec during the period of restricted access. Uneaten shreds were collected and weighed to the nearest $0.1 \mathrm{gm}$. In the third group, 11 rats were given unrestricted access to lard beginning $1.5 \mathrm{hr}$ after insulin injection.

Several criteria were established which resulted in the exclusion of some subjects from statistical analyses. (1) Animals were eliminated if they did not consume the appropriate number of calories (approximately $7.9 \mathrm{kcal}$ ) of any particular food during the test. This criterion resulted in elimination of 6 of the 25 rats trained to drink glucose. (2) Animals were excluded if they failed to drink at least $4.5 \mathrm{ml}$ of saccharin. Since it was difficult to train rats to drink large volumes of saccharin, we arbitrarily chose a criterion of $4.5 \mathrm{ml}$ to assure that a reasonable volume would be consumed by all rats included in the analysis. Seven of 20 rats failed to meet this criterion during the test. (3) Finally, in order to assure that the stress of glucoprivation contributed minimally to our results, we eliminated subjects whose blood glucose values did not return to normal within the $6 \mathrm{hr}$ period after insulin injection. One rat was eliminated from the saccharin test by this criterion.

After the feeding tests were completed, these experiments were repeated in naive rats in order to determine the effects of the same ingested substances on catecholamine turnover during the postglucoprivic period. Since we found no significant effect of insulin on brain catecholamine concentrations in the absence of AMT, catecholamine concentrations from all turnover experiments were calculated and expressed as a percentage of untreated control values.

Paired and nonpaired bidirectional $t$ tests were used to analyze blood glucose, postglucoprivic feeding, and catecholamine content data. Statistical results from each parameter were confirmed using one-way analysis of variance.

\section{Results}

The consumption of $2.5 \mathrm{gm}$ of pelleted laboratory food ingested within a brief access period during ongoing glucoprivation abolished postglucoprivic feeding (Fig. 1). Ingestion of smaller quantities of pelleted food at this time had no effect on the magnitude of delayed feeding. The blood glucose values recorded during this study are displayed in Figure 2. Spontaneous glucorestoration in insulin-treated rats occurred between 5 and $6 \mathrm{hr}$ postinjection both in the absence of food and after consumption of $1.0 \mathrm{gm}$ or less of pelleted food. However, in animals permitted to ingest $2.5 \mathrm{gm}$ of food, blood glucose concentrations returned to preinjection base line values by 3 to $4 \mathrm{hr}$ after insulin injection.

Delayed feeding observed from 4 to $6 \mathrm{hr}$ after limited access to a variety of substances offered during ongoing glucoprivation is shown in Figure 3. Saccharin ingestion and cardboard chewing failed to abolish postglucoprivic feeding. In the latter test, although significant quantities of flavored cardboard were not consumed $(0.19 \pm 0.15$ $\mathrm{gm})$, the amount of time spent chewing and shredding occupied a considerable fraction of the total time animals had access to this substance $(7.1 \pm 2.5 \mathrm{~min})$. Lard and fructose consumption $(0.9 \mathrm{gm}$ and at least $9.5 \mathrm{ml}$ of an $18 \%$ solution, respectively) significantly attenuated post-

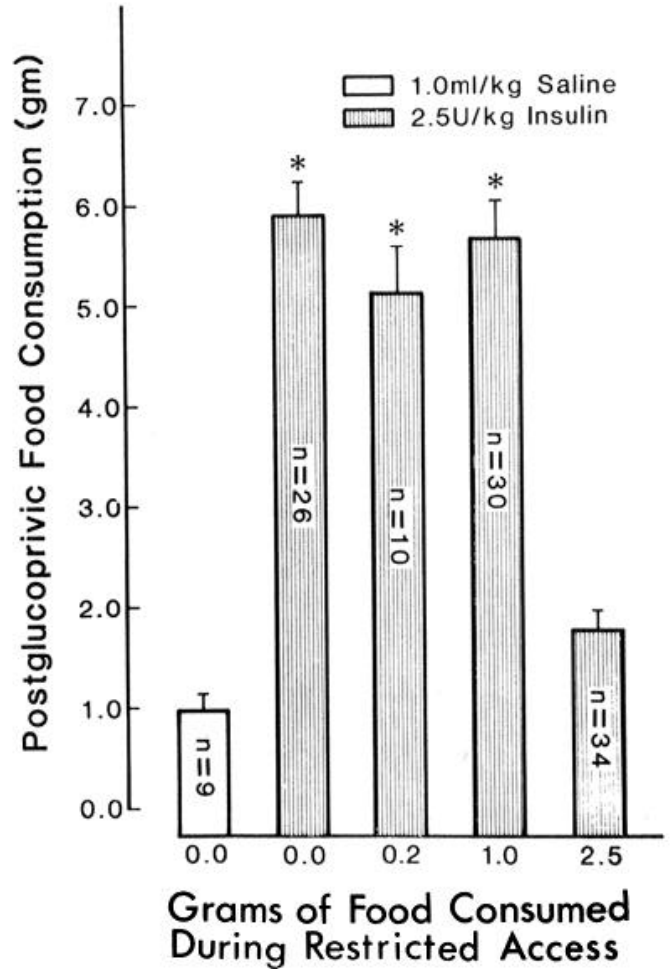

Figure 1. Amount of pelleted rodent food consumed during delayed glucoprivic feeding trials conducted from 6 to $8 \mathrm{hr}$ after subcutaneous insulin (Iletin, 2.5 units $/ \mathrm{kg}$ ) or saline $(1.0 \mathrm{ml} / \mathrm{kg}$ ) injections. Insulin-treated rats were allowed to ingest from 0.0 to $2.5 \mathrm{gm}$ of pelleted food from 1.5.to $2 \mathrm{hr}$ postinjection. Delayed glucoprivic feeding was significantly reduced only in rats ingesting at least $2.5 \mathrm{gm}$ of food. $(*=p \leq 0.01$ versus saline controls.) The data presented are the means \pm SEM.

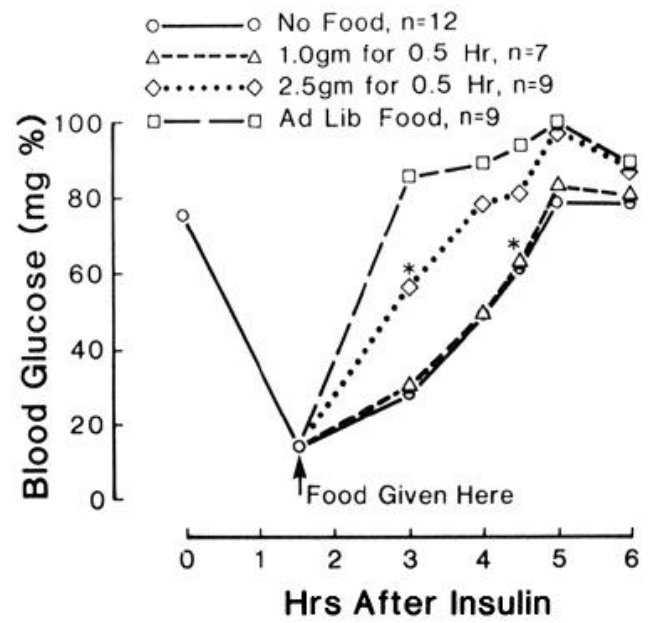

Figure 2. Blood glucose concentrations from insulin-injected rats allowed to consume $0,1.0$, or 2.5 gm of pelleted food from 1.5 to $2 \mathrm{hr}$ after subcutaneous insulin injections. Also shown are blood glucose values from insulin-treated rats permitted to feed ad libitum from 1.5 to $6 \mathrm{hr}$ following insulin. The asterisks identify blood glucose values that are significantly less than preinjection levels $(p \leq 0.05)$.

glucoprivic feeding. However, the magnitude of delayed feeding observed following each of these nutrients remained statistically greater than that observed after pellet or glucose consumption, each of which abolished 


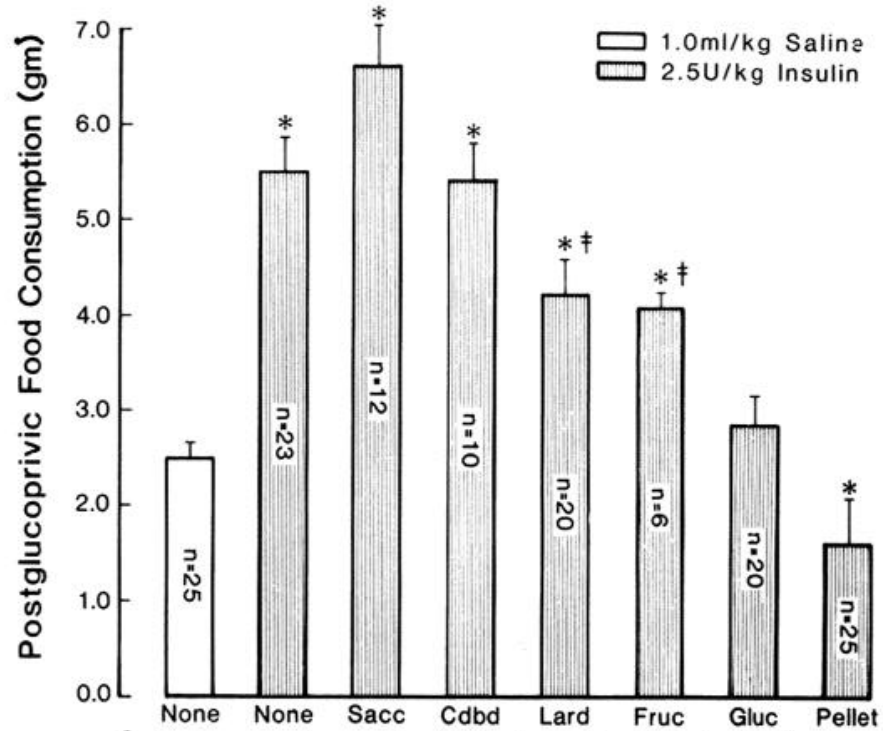

Substance Ingested During Restricted Access

Figure 3. Consumption of pelleted food during delayed glucoprivic feeding trials conducted from 6 to $8 \mathrm{hr}$ after subcutaneous insulin administration. Animals were allowed to ingest a variety of noncaloric or qualitatively different isocaloric substances from 1.5 to $2 \mathrm{hr}$ after insulin injections. Noncaloric substances failed to alter the amount of delayed glucoprivic feeding significantly. The ingestion of lard or fructose attenuated delayed glucoprivic feeding $(\ddagger=p \leq 0.05$ versus insulin, no food), but the amount eaten differed significantly from the intake observed in saline-treated animals $(*=p \leq 0.05)$. Ingestion of either glucose or pelleted food during the restricted access period totally abolished delayed glucoprivic feeding. The data presented are the means \pm SEM. The abbreviations used are: Cdbd, flavored cardboard; Fruc, fructose; Gluc, glucose; Sacc, saccharin.

postglucoprivic food intake. Likewise, postglucoprivic feeding was not abolished by unrestricted access to lard, even though rats consumed approximately $26.5 \mathrm{kcal}(3.02$ $\pm 1.77 \mathrm{gm})$ of lard prior to the delayed feeding test. In this test, rats ate $5.71 \pm 1.38 \mathrm{gm}$ of pelleted food after insulin alone and $4.65 \pm 1.28 \mathrm{gm}$ when insulin injection was followed by lard consumption $(p>0.05)$. Figure 4 presents the blood glucose concentrations that accompanied ingestion of the various foods. Substances that failed to prevent delayed feeding (insulin alone, saccharin, lard, fructose, and flavored cardboard) also failed to accelerate glucorestoration. Conversely, glucose and pellet consumption abolished delayed glucoprivic feeding and accelerated the return of blood glucose concentrations to normal values.

The effects of various substances consumed during the insulin-elicited glucoprivic period on postglucoprivic hypothalamic NE turnover are seen in Figure 5. Ingestion of either pelleted food or glucose solution by insulintreated rats normalized apparent rates of hypothalamic NE turnover by $2 \mathrm{hr}$ post-AMT injection to values indistinguishable from those seen in saline-injected subjects. In contrast, hypothalamic NE turnover in rats that consumed lard, fructose, or saccharin during glucoprivation did not differ from the rates obtained in insulin-treated rats not permitted to feed. As reported elsewhere (Bellin

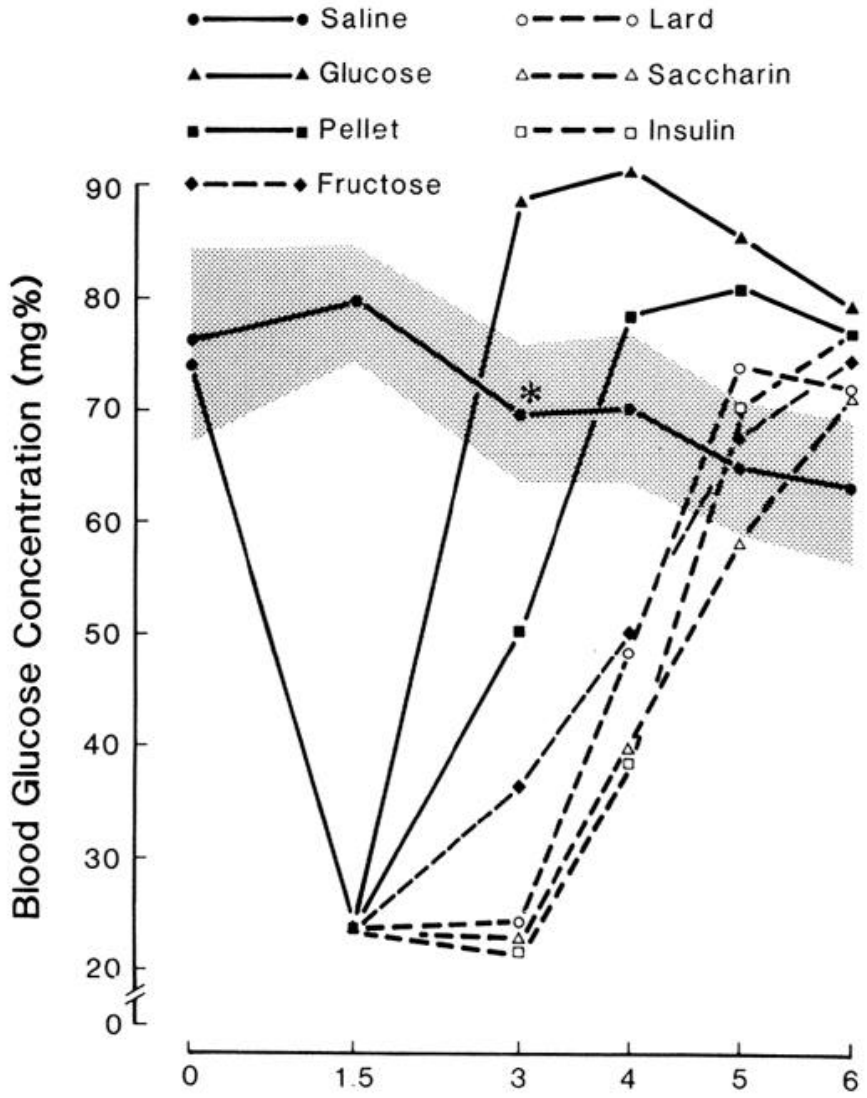

Hrs After Insulin or Saline Injection

Figure 4. Blood glucose concentrations after consumption of a variety of noncaloric or qualitatively different isocaloric substances from 1.5 to $2 \mathrm{hr}$ after subcutaneous insulin injection. The stippled area represents the $95 \%$ confidence interval for blood glucose values sampled from saline-treated rats $(*=p$ $\leq 0.001$ versus all treatments at $3 \mathrm{hr}$ postinjection).

and Ritter, 1981a, b), turnover of telencephalic NE and dopamine did not appear to be related consistently to either insulin treatment or food ingestion.

\section{Discussion}

Ingestion of $7.9 \mathrm{kcal}$ as glucose or pelleted rodent food from 1.5 to $2 \mathrm{hr}$ after insulin injection abolished delayed glucoprivic feeding and restored hypothalamic NE turnover during the postglucoprivic period to rates comparable to those observed in control rats. However, ingestion of $7.9 \mathrm{kcal}$ as fructose or fat, ingestion of quantities of pelleted food less than $7.9 \mathrm{kcal}$, and orogastric stimulation by non-nutritive substances all failed to abolish either of these glucoprivic responses.

The fact that glucose and pellet ingestion were the only treatments which elevated blood glucose concentrations suggests that glucorestoration may be the mechanism which accounts for the effectiveness of these particular foods in abolishing the delayed feeding and normalizing hypothalamic NE turnover (however, see Bellin and Ritter, 1981b). Of the metabolic substrates derived from the foods used in this experiment, only glucose is trans. ported directly into and utilized by brain tissue. Thus, the effectiveness of glucose-elevating foods in totally 


\section{HYPOTHALAMUS}

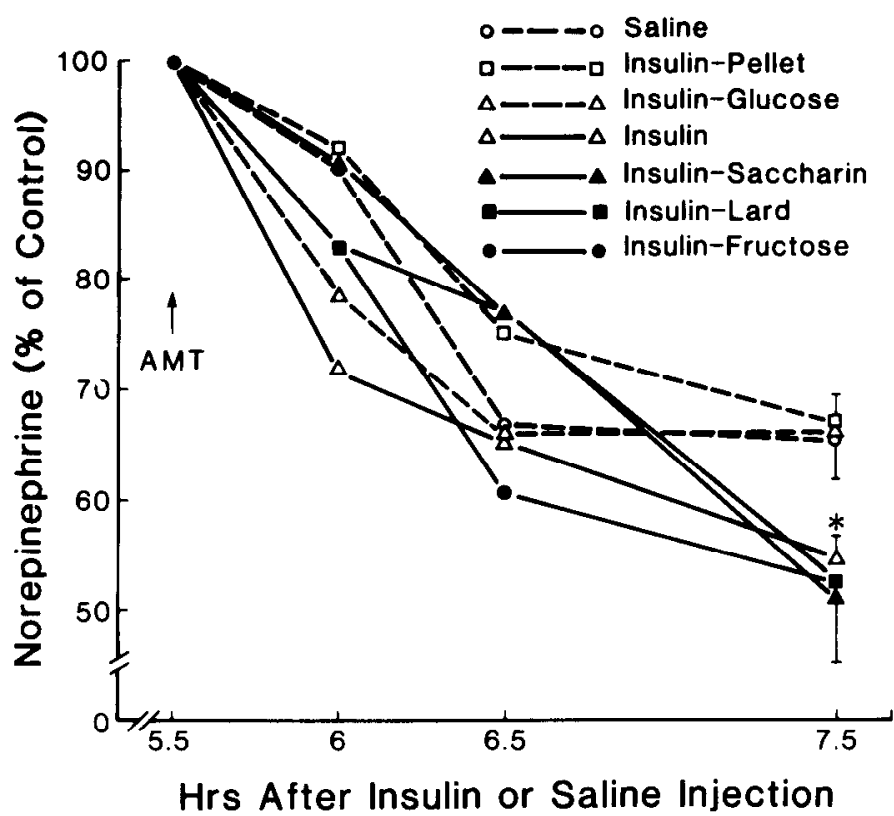

Figure 5. Effects of various ingested substances on the relative rates of hypothalamic NE turnover during the postglucoprivic period after insulin injection. Noncaloric or qualitatively different isocaloric substances were ingested from 1.5 to $2 \mathrm{hr}$ after insulin injections. Turnover was estimated by the rate of decline of $\mathrm{NE}$ concentration after synthesis inhibition by $\alpha$ methyl-p-tyrosine $(350 \mathrm{mg} / \mathrm{kg}$, s.c.). Ingestion of $7.9 \mathrm{kcal}$ of pelleted food or glucose solution normalized hypothalamic NE turnover rates after insulin injection ( $p \geq 0.10$ versus saline), but other ingested substances had no effect $\left(^{*}=p \leq 0.05\right.$, insulin, insulin-saccharin, insulin-lard, and insulin-fructose versus saline). Values are expressed as the mean $\pm \mathrm{SD}$.

abolishing glucoprivic responses might result from the ability of glucose to act at brain receptors controlling these responses. With respect to hypothalamic NE turnover, our data indeed suggest that restoration of a fuel available to brain tissue is both necessary and sufficient to normalize turnover rates after glucoprivation. The results of glucose ingestion that are reported here are supported by those of a related study, utilizing the same delayed feeding paradigm, in which intravenous infusions of both glucose and $\beta$-hydroxybutyrate, both of which are utilized by the brain in vivo, normalized hypothalamic NE turnover after a glucoprivic episode. However, infusion of fructose, which does not enter the brain, failed to normalize NE turnover (Bellin and Ritter, 1981b).

The conditions for the abolition of glucoprivation-induced feeding are more complicated than those for the normalization of NE neuron activity. Although it appears that glucorestoration accompanying ingestion of pelleted food or glucose solutions is sufficient to abolish delayed glucoprivic feeding, our infusion studies (Bellin and Ritter, 1981b) clearly demonstrate that restoration of blood glucose concentration in the absence of actual ingestion does not abolish delayed feeding. Therefore, the effectiveness of ingested glucose in abolishing the feeding response must depend on some combination of preab- sorptive stimuli and glucorestoration. It is possible, for example, that an orally mediated endocrine or neural response must accompany glucorestoration in order to terminate feeding (McHugh et al., 1975; Kraly et al., 1978; McHugh and Moran, 1978; Granneman and Friedman, 1980; Myers and McCaleb, 1980).

Specification of the conditions required to abolish delayed glucoprivic feeding is complicated further by our observation that delayed feeding was diminished significantly (although not abolished) by ingestion of fat or fructose. Thus, it may be that a portion of the signal to terminate feeding may arise from restoration of nutrients specifically to peripheral tissues (Russek, 1970; Novin et al., 1973; Stricker et al., 1977; Stricker and Rowland, 1978; Rowland and Stricker, 1979). Fat and fructose may act at peripheral receptors while failing to gain access to cooperative receptors within the brain. Alternatively, the attenuation of delayed glucoprivic feeding by fat or fructose may not be related directly to the glucoprivic stimulus but may arise from an independent satiety signal of peripheral origin which competes with the glucoprivic stimulus (Granneman and Friedman, 1980).

The observation that delayed glucoprivic feeding can be attenuated by lard or fructose in the absence of any diminution of hypothalamic NE turnover suggests that the attenuation of feeding is not brought about by a reduction in NE neuron activity, at least as reflected in analyses of the entire hypothalamus. The dissociation of feeding and NE turnover suggests that NE neurons may not play a causal role in the persistence of feeding after glucoprivation. This view is supported by our studies with glucose infusions (Bellin and Ritter, 1981b). In these studies, intravenous glucose infusions did not attenuate delayed glucoprivic feeding, even though normal hypothalamic NE turnover rates were restored. However, a role for $\mathrm{NE}$ neurons in sustaining glucoprivic feeding cannot be ruled out conclusively until NE turnover is examined in specific hypothalamic nuclei during and after glucoprivic challenge. Such turnover studies have been performed in spontaneously feeding rats by Van der Gugten et al. (1977; see also Van der Gugten and Slangen, 1977). They found that increased turnover was associated with feeding only in specific nuclei which have been implicated by other data in ingestive control (Grossman, 1962; Booth, 1967; Davis and Keesey, 1971; Leibowitz, 1975). Such an analysis may prove fruitful in further elucidating the role of $\mathrm{NE}$ neurons in glucoprivic feeding.

The results of these experiments indicate that, although glucoprivic feeding is initiated by a specific biochemical stimulus, the termination of this feeding requires a constellation of signals which appear to include systemic glucorestoration and preabsorptive cues. In this regard, the glucoprivic control of feeding provides a biochemically circumscribed model system having attributes of spontaneous feeding.

\section{References}

Bellin, S. I., and S. Ritter (1981a) Insulin-induced elevation of hypothalamic norepinephrine turnover persists after glucoprivation unless feeding occurs. Brain Res. 217: 327-337.

Bellin, S. I., and S. Ritter (1981b) Disparate effects of infused 
nutrients on delayed glucoprivic feeding and hypothalamic norepinephrine turnover. J. Neurosci. 1: 1347-1353.

Booth, D. A. (1967) Localization of the adrenergic feeding system in the rat diencephalon. Science 158: 515-517.

Cooper, J. R., F. E. Bloom, and R. H. Roth (1978) The Biochemical Basis of Neuropharmacology, pp. 134-139, Oxford University Press, New York.

Costa, E. (1970) Simple neuronal models to estimate turnover rate of noradrenergic transmitters in vivo. Adv. Biochem Psychopharmacol 2: 169-204.

Davis, J. R., and R. E. Keesey (1971) Norepinephrine-induced eating: Its hypothalamic locus and an alternate interpretation of action. J. Comp. Physiol. Psychol. 77: 394-402.

Engeset, R. M., and R. C. Ritter (1980) Intracerebroventricular $2-D G$ causes feeding in the absence of other signs of glucoprivation. Brain Res. 202: 229-233.

Fpstein, A. N., S. Nicolaides, and R. Miselis (1975) The glucoprivic control of food intake and glucostatic theory of feeding behavior. In Neural Integration of Physiological Mechanisms and Behavior, G. J. Mogenson and F. R. Calarescu, eds., pp. 148-168, University of Toronto Press, Toronto.

Friedman, E., N. Starr, and S. Gershon (1973) Catecholamine synthesis and the regulation of food intake in the rat. Life Sci. 12: 317-326.

Friedman, M. I., and E. M. Stricker (1976) The physiological psychology of hunger: A physiological perspective. Psychol. Rev. 83: 409-431.

Goodman, M. H. (1970) Regulation of lipid metabolism. Physiologist 13: 75-88.

Granneman, J., and M. I. Friedman (1980) Interaction of hepatic and cerebral receptors in the control of feeding stimulated after the recovery from acute glucoprivation in rats. Soc. Neurosci. Abstr 6: 529.

Grossman, S. P. (1960) Eating or drinking elicited by adrenergic stimulation of the hypothalamus. Science 132: 301-302.

Grossman, S. P. (1962) Direct adrenergic and cholinergic stimulation of hypothalamic mechanisms. Am. J. Physiol. 202: 872-882.

Grossman, S. P. (1975) Role of the hypothalamus in the regulation of food and water intake. Psychol. Rev. 82: 200-224.

Houpt, T. R. (1974) Stimulation of food intake in ruminants by 2-deoxy-D-glucose and insulin. Am. J. Physiol. 227: 161-167.

Houpt, T. R., and H. E. Hance (1977) Threshold levels of 2deoxy-D-glucose for the hyperglycemic response: Dog and goat compared. Life Sci. 21: 513-518.

Jacobowitz, D. M., T. Cooper, and N. B. Barner (1967) Histochemical and chemical studies of the localization of adrenergic and cholinergic nerves in normal and denervated cat hearts. Circ. Res. 20: 289-298.

Kraly, S. F., W. J. Carty, and G. P. Smith (1978) Effect of pregastric food stimuli on meal size and intermeal interval in the rat. Physiol. Behav. 20: 779-784.

Leibowitz, S. F. (1975) Pattern of feeding and drinking produced by hypothalamic norepinephrine injection in the satiated rat. Physiol. Behav. 14: 731-742.

Lorden, J. F., G. A. Oltmans, and D. L. Margules (1975) Central catecholamine levels in genetically obese mice (obob and dbdb). Brain Res. 96: 390-394.

Mackay, E. M., J. W. Calloway, and R. H. Barnes (1940) Hyperalimentation in normal animals produced by protamine insulin. J. Nutr. 20: 59-66.

McCaleb, M. L., R. D. Myers, G. Singer, and G. Willis (1979) Hypothalamic norepinephrine in the rat during feeding and push-pull perfusion with glucose, 2-DG or insulin. Am. J. Physiol. 236: R312-R321.

McHugh, P. R., and T. H. Moran (1978) Accuracy of the regulation of caloric ingestion in the rhesus monkey. Am. J. Physiol. 235: R29-R34.
McHugh, P. R., T. H. Moran, and G. N. Barton (1975) Satiety: A graded behavioral phenomenon regulating caloric intake. Science 190: 167-169.

McQueen, A., S. Armstrong, G. Singer, and R. D. Myers (1976) Noradrenergic feeding system in monkey hypothalamus is altered by localized perfusion of glucose, insulin, 2-DG and eating. Pharmacol. Biochem. Behav. 5: 491-494.

Miselis, R. R., and A. N. Epstein (1975) Feeding induced by intracerebroventricular 2-deoxy-D-glucose in the rat. Am. J. Physiol. 229: 1438-1447.

Myers, R. D., and M. L. McCaleb (1980) Feeding: Satiety signal from intestine triggers brain's noradrenergic mechanism. Science 209: 1035-1037.

Novin, D., D. A. Vanderweele, and M. Rezek (1973) Infusion of 2-deoxy-D-glucose into the hepatic-portal system causes eating: Evidence for peripheral glucoreceptors. Science 181: 858860.

Oldendorf, W. H. (1971) Brain uptake of radiolabeled amino acids, amines, and hexoses after arterial injection. Am. J. Physiol. 221: 1629-1639.

Ritter, R. C., and A. N. Epstein (1975) Control of meal size by central noradrenergic action. Proc. Natl. Acad. Sci. U. S. A. 72: $3740-3743$.

Ritter, R. C., and M. Neville (1976) Hypothalamic noradrenaline turnover is increased during glucoprivic feeding. Fed. Proc. 35: 642.

Ritter, R. C., M. Roelke, and M. Neville (1978) Glucoprivic feeding behavior in absence of other signs of glucoprivation. Am. J. Physiol. 234: E617-E621.

Ritter, S., C. D. Wise, and L. Stein (1975) Neurochemical regulation of feeding in the rat: Facilitation by $\alpha$-noradrenergic, but not dopaminergic receptor stimulants. J. Comp. Physiol. Psychol. 88: 778-784.

Rowland, N., and E. M. Stricker (1979) Differential effects of glucose and fructose infusions on insulin-induced feeding in rats. Physiol. Behav. 22: 387-389.

Russek, M. (1970) Demonstration of the influence of an hepatic gluco-sensitive mechanism on food intake. Physiol. Behav. 5: 1207-1209.

Russek, M. (1975) Current hypotheses in the control of feeding behavior. In Neural Integration of Physiological Mecha. nisms and Behavior, G. J. Mogenson and F. R. Calarescu, eds., pp. 128-147, University of Toronto Press, Toronto.

Saifer, A., and S. Gerstenfeld (1958) The photometric microdetermination of blood glucose with glucose oxidase. J. Lab. Clin. Med. 51: 448-460.

Slangen, J. L., and N. E. Miller (1969) Pharmacological tests for the function of hypothalamic norepinephrine in eating behavior. Physiol. Behav. 4: 543-552.

Slusser, P. G., and R. C. Ritter (1980) Increased feeding and hyperglycemia elicited by intracerebroventricular 5-thioglucose. Brain Res. 202: 474-478.

Smith, G. P., and A. N. Epstein (1969) Increased feeding in response to decreased glucose utilization in the rat and monkey. Am. J. Physiol. 217: 1083-1087.

Smith, J. C., and D. F. Foster (1980) Some determinants of intake of glucose + saccharin solutions. Physiol. Behav. 25: 127-133.

Smith, J. C., T. W. Castonquay, D. F. Foster, and L. M. Bloom (1980) A detailed analysis of glucose and saccharin drinking in the rat. Physiol. Behav. 24: 173-176.

Spitzer, J. J. (1973) CNS and fatty acid metabolism. Pharmacologist 16: 55-68.

Stricker, E. M., and N. Rowland (1978) Hepatic versus cerebral origin of stimulus for feeding induced by 2-deoxy-D-glucose in rats. J. Comp. Physiol. Psychol. 92: 126-132.

Stricker, E. M., N. Rowland, C. F. Saller, and M. I. Friedman (1977) Homeostasis during hypoglycemia: Central control of 
adrenal secretion and peripheral control of feeding. Science 196: 79-81.

Thompson, D. A., and R. G. Campbell (1977) Hunger in humans induced by 2-deoxy-D-glucose: Glucoprivic control of taste preference and food intake. Science 198: 1065-1068.

Van der Gugten, J., and J. Slangen (1977) Release of endogenous catecholamines from rat hypothalamus in vivo related to feeding and other behaviors. Pharmacol. Biochem. Behav. 7: 211-219.
Van der Gugten, J., E. R. deKloet, D. H. G. Versteeg, and J. L. Slangen (1977) Regional hypothalamic catecholamine metabolism and food intake regulation in the rat. Brain Res 135: $325-336$.

Weiner, N. (1974) A critical assessment of methods for the determination of monoamine synthesis turnover rates in vivo. In Neuropharmacology of Monoamines and Their Regulatory Enzymes, E. Usdin, ed., pp. 143-159, Raven Press, New York. 